\title{
De la tensión en el ejercicio de los roles de género a la violencia conyugal como pauta relacional*
}

\section{From tension in the exercise of gender roles to marital violence as a relational pattern}

\author{
Diana Marcela Alzate-Torres**
}

\section{Resumen}

Objetivo. En este artículo se presentan resultados de una investigación sobre violencia conyugal realizada con parejas de Manizales cuyo propósito fue analizar las conexiones entre tensiones generadas en el ejercicio de los roles de género y la emergencia de la violencia en la relación de pareja. Metodología. Se empleó la perspectiva cualitativa desde el enfoque hermenéutico. Resultados. Se reconoce que los estereotipos de género son centrales en la conformación de la pareja, en la formación de fricciones, desacuerdos y conflictos producidos a partir de la no correspondencia (o la insatisfactoria correspondencia) entre expectativas frente al rol de género propio y del otro/a, y el ejercicio real de estos. Conclusión. El surgimiento de la violencia se genera como vía de resolución o como forma de decir lo que no se alcanza a expresar de otras maneras, como estrategia para la reorganización del control, entre otras razones para irrumpir en esta interacción

Palabras clave: violencia conyugal, expectativas y roles de género, estereotipos de género, pauta relacional.

\begin{abstract}
Objective: This article presents the results of a research on marital violence carried out with couples from the city of Manizales, with the purpose of analyzing the connections between tensions generated in the exercise of gender roles and the emergence of violence in the relationship. Methodology: The qualitative perspective from the hermeneutical approach was used. Results: It is recognized that gender stereotypes are central to the formation of the couple, in the emergence of frictions, disagreements and conflicts produced from the non-correspondence (or unsatisfactory correspondence) between the expectations regarding the role of gender and the other, and the actual exercise of these. Conclusion: The emergence of violence is generated as a means of resolution or as a way of saying what cannot be expressed in other ways as a strategy for the reorganization of control among other possible reasons for breaking into this interaction.
\end{abstract}

Key words: marital violence, expectations and gender roles, gender stereotypes, relational pattern.

\footnotetext{
*Artículo derivado de la investigación "Violencia conyugal: un análisis desde el lugar de los roles de género en las relaciones de pareja”, como requisito para optar al título de Magíster en Intervención en Relaciones Familiares del Departamento de Estudios de Familia de la Universidad de Caldas, Manizales, Colombia, 2017.

** Universidad de Caldas. Manizales, Colombia. E-mail: diana.alzate@ucaldas.edu.co

(D) orcid.org/0000-0003-2174-7886
} 


\section{Introducción}

La violencia conyugal comprende formas de relación tan antiguas como la historia misma (Hernández, 2014), que han sido denunciadas por mujeres que han asumido la tarea de su visibilización social y política como un fenómeno estructural en las sociedades que afecta todas las esferas y ámbitos (no solo los privados, como se le ha pretendido reconocer). Estas mujeres, entre las que resaltan Rubin (1975) y Scott y Butler (1992), comparten la idea de que su existencia obedece a la aceptación social de las desigualdades entre los hombres y las mujeres. Sus aportes a la organización de colectivos con perspectiva feminista, comprometidos con la defensa de la igualdad entre los géneros, contribuyó en gran medida a posicionar la violencia que tiene lugar en los espacios privados como un problema de alta relevancia en el escenario político, desde la segunda década del siglo anterior.

La existencia de la violencia intrafamiliar y específicamente la de género es un fenómeno propio de los problemas de la sociedad. Esta, tradicionalmente, sus instituciones y su núcleo fundamental, la familia, transmiten patrones de comportamiento sobre el significado de ser hombre y mujer. (Hernández, 2014, p. 13)

De esta manera, se reconoce que el problema de la violencia en la pareja obedece a la comprensión de las dinámicas particulares que ocurre en la cotidianidad de la vida de hombre y mujer, además del reconocimiento como proceso transitado por transformaciones asociadas a cambios sociales, culturales, económicos y políticos ocurridos durante las últimas décadas. Estos han conducido al incremento de nuevas dinámicas en estas relaciones, conceptualizadas por autores como Giddens (2000) e Illouz (2012), como rasgos o tendencias del emparejamiento, tales como: la proveeduría compartida de la familia ante la necesidad económica y el interés personal de las mujeres por trabajar fuera de los hogares; la reducción del número de hijos, debido a la posibilidad de decisión de las mujeres frente a la maternidad; la mayor presencia de familias divorciadas, de uniones sucesivas, entre otras, que han impactado el ejercicio de los roles de género, pero que no por ello lo han hecho también de carácter similar en la forma de representar dichos roles, dado que cumplen un papel determinante en el surgimiento de tensiones asociadas a las expectativas insatisfechas, respecto a lo que cada uno espera del otra/o como mujer y como hombre.

La importancia de la comprensión de las dinámicas particulares de la violencia conyugal que tiene lugar en la cotidianidad de la vida de la pareja, se sustenta en el reconocimiento de los elementos de tradición y de cambio en el ejercicio de los roles de género, que en correspondencia con las expectativas de los roles propios y del otro, propicia tensiones algunas de ellas definidas desde pautas de interacción violenta en la pareja En este sentido, el punto de partida para la investigación fue el reconocimiento de la historia, las situaciones y los relatos de vida de hombres y mujeres, con el fin de que se analizaran en los posicionamientos de género. 
De la tensión en el ejercicio de los roles de género a la violencia conyugal como pauta relacional

Se buscó explorar los modos particulares desde los cuales los integrantes de las parejas afectadas por la violencia asumen los roles de género presentes en la estructuración de las dimensiones: 1. Organizacional, que comprende la vida doméstica, el cuidado, la proveeduría económica; y 2. Relacional, se identifica la comunicación, el afecto y la sexualidad. Cada uno de ellos permitió reconocer las tensiones producidas en las relaciones de pareja, por la insatisfacción que se genera entre las expectativas y el ejercicio real de los roles, que se expresan en prácticas y discursos en los que los integrantes de la pareja se distancian de sus roles o que conlleva a situaciones de violencia.

Así, entre los hallazgos más significativos de la investigación se encontró que a partir de las tensiones en las relaciones de las parejas se ha originado el surgimiento de la violencia, bien sea como vía de resolución, como forma de decir lo que no se alcanza a expresar de otras maneras, como estrategia para la reorganización del control, entre otras posibles razones para irrumpir en esta pauta de interacción. De igual forma, las reflexiones generadas giraron en torno a aspectos como: lo gestual, el silencio, la sujeción y la separación que hacen parte del acuerdo implícito rígido sobre el cual se sustenta la violencia en la pareja (Perrone y Nannini, 2007).

\section{Referente teórico y conceptual}

Los marcos teórico-conceptuales, sobre los cuales se asumió la investigación, fueron los propuestos por perspectivas psicológicas y sociológicas posmodernas que han abordado los rasgos o tendencias del emparejamiento en la modernidad en asuntos como: la proveeduría compartida de los hogares, la reducción del número de hijos, la mayor presencia de uniones sucesivas, entre otras, que han impactado el ejercicio de los roles de género; aspectos abordados por autores como Giddens (2000), Beck y Beck-Gernsheim (2001) e Illouz (2012).

De otra parte, se asumió la mirada epistemológica del construccionismo social, con el fin de comprender que el problema de la violencia conyugal obedece a las dinámicas particulares en la cotidianidad de la vida del hombre y la mujer, además del reconocimiento de categorías como: los roles de género, las relaciones de pareja, la conyugalidad, los discursos y las prácticas que sustentaron el objeto de estudio a partir de una mirada relacional.

En el marco de las dinámicas familiares y para efectos de los intereses de conocimiento del presente artículo, se retomaron las relaciones de género con la plena intención de connotar las características, los roles y funciones que son atribuibles tanto a hombres como a las mujeres. En este mismo sentido, como lo refieren Facio y Fries (1999), existen diferencias individuales y en los colectivos de hombres y mujeres, pero que no debe ser motivo para señalarlas en valorar más a unos que a otros, sino ante todo para reconocer al ser humano. 
La creencia de que todas las personas - mujeres y hombresvalemos en tanto seres humanos igualmente diferentes e igualmente semejantes, tanto dentro de cada uno de estos grandes colectivos humanos, como en el colectivo de hombres y mujeres, es decir, si bien somos todos seres humanos, a la vez somos diferentes en términos de individualidades y en términos de colectivos. (Facio y Fries, 1999, p. 264)

De igual manera, se situó la lectura de las relaciones de género desde el reconocimiento de las potencialidades, roles y funciones de hombres y mujeres, no como escenarios separados sino desde las relaciones que se potencian entre ellos, al respecto Scott y Butler (como se citó en Lamas, 1999) plantean:

Una ventaja de usar el género para designar las relaciones sociales entre los sexos: mostrar que no hay un mundo de las mujeres aparte del mundo de los hombres, que la información sobre las mujeres es necesariamente información sobre los hombres. Usar esta concepción de género lleva a rechazar la idea de las esferas separadas. (p. 331)

Lo anterior reafirma la necesidad de hacer una lectura integral del género, analizando las relaciones, lo que significan y como se ubican en la sociedad y para el caso específico, la familia, el ser hombre y el ser mujer, desde los roles, las limitaciones y las expectativas que tiene cada uno, además en las diferentes formas de interacción de los seres humanos. Por consiguiente, las relaciones de género dentro de la familia, implican establecer conexiones entre las ideas personales y las construcciones sociales, Kaufman (como se citó en Iturrieta, 2001):

Los acercamientos desde la perspectiva de género permiten ilustrar la construcción social de las familias y de las relaciones de hombres y mujeres. De modo que el análisis desde este enfoque, no se sitúa solo en el mundo socialmente construido de la persona, sino que, desde una perspectiva crítica, se pregunta por la forma en que la realidad subjetiva, es decir, la realidad válida para una persona, se configura y organiza, así como cuáles son las trayectorias históricas o relaciones sociales en las que esa persona está inmersa y por lo tanto, desde dónde construye su realidad subjetiva. (p. 70)

De otra parte, en lo que se refiere a las relaciones de pareja entre hombre y mujer, es decir la conyugalidad en palabras de Illanes (2011), “es un vínculo, en ella participan dos-los cónyuges- 
De la tensión en el ejercicio de los roles de género a la violencia conyugal como pauta relacional

de manera directa; sin el marido o sin la mujer la conyugalidad, en tanto relación, no existe y al desaparecer el complemento, tampoco existirían los cónyuges en su individualidad” (p. 149). La conyugalidad se comprendió desde dos dimensiones de análisis: la primera, la organizativa, que vincula a la pareja con lo doméstico y los procesos de socialización familiar; y la íntima, es decir la construcción de la relación de pareja (Illanes, 2011). Aspectos que fueron retomados con el objetivo de visibilizar las prácticas y discursos en las relaciones de pareja desde las dimensiones prácticas y simbólicas.

Estudiar la conyugalidad en la actualidad implica inevitablemente pensar en términos iniciales en una unidad analítica compuesta por dos personas que crean - con más o menos problemas- una biografía común: el vínculo. Luego, significa pensar en la relación de este par con un entorno social que limita o libera su accionar a través de mecanismos que regulan las expectativas en torno al amor y sexualidad, así como del rol social que debe asumir cada quien en la pareja. (Illanes, 2011, p. 5)

En la conyugalidad se pueden sostener vínculos caracterizados por relaciones violentas que atentan contra los derechos humanos e inhiben el desarrollo de las personas, además se caracterizan por una dinámica relacional destructiva entre el hombre y la mujer, es así, que "para comprender y abordar el fenómeno de la violencia en la pareja establecen como premisa fundamental que la violencia es un fenómeno interaccional, donde ambos participantes de la interacción violenta son responsables de la secuencia involucrada" (Perrone y Nannini, 2007, p. 28).

Dentro de la dinámica relacional destructiva de la familia, y específicamente en la pareja, se establece un círculo interactivo caracterizado por diversos dispositivos que potencian las prácticas violentas, y que como lo refiere Palacio (2004), se utilizan expresiones físicas (huellas que atentan contra el cuerpo) y verbales (empleo de la palabra para herir al otro). Cabe agregar que,

La violencia establece una circularidad relacional que entrelaza a todos sus integrantes. Su expresión es de manera consciente e inconsciente e implica un aprendizaje a través de procesos de socialización que legitiman la utlización de estos dispositivos con las actuaciones propias de los roles que se asignan y se construyen en la organización familiar. (Palacio, 2004, p. 126)

En efecto, se identificaron pautas de interacción centradas en la relación y no en las características individuales de las personas, en donde se estableció un modelo circular que se 
distanció de las dicotomías víctima y victimario, debido a que "parece más razonable hablar de actores de la violencia, se llamarán participantes a las personas que se hallan presentes en el momento de la acción violenta, la propuesta es mostrar que existen modelos de interacciones que conducen a la violencia” (Perrone y Nannini, 2007, p. 32).

Para ello, se estructuró la violencia de género en las relaciones de pareja a partir de los roles que se construyen en el lugar del hombre y la mujer, con el fin de analizar las prácticas y discursos de

\begin{abstract}
Quienes sufren violencia a la luz de su posición en la familia, en respuesta a las construcciones sociales y mandatos de género incorporados mediante el aprendizaje sociocultural transmitido de generación en generación, que responde a cómo debemos ser hombres y mujeres en sociedad. (Hernández, 2014, p. 18)
\end{abstract}

Finalmente, se pretendió que los discursos y prácticas que permean las relaciones no se visibilizaran como dos aspectos desarticulados, al contrario encontrar una conexión entre ellos iniciando por reconocer que desde la reflexividad se pueden abordar de forma discursiva las actividades de las personas para que encuentren motivos, razones y justificaciones de por qué las hacen. En este sentido, la reflexividad, entonces, no se debe entender como mera "autoconciencia, sino como el carácter registrado del fluir corriente de una vida social" (Giddens, 2003, p. 41).Y el obrar relacionado con las acciones en las que participan los seres humanos, concierne a "sucesos de los que un individuo es el autor, en el sentido de que el individuo pudo, en cada fase de una secuencia dada de conducta haber actuado diferente" (Giddens, 2003, p. 46).

\title{
Metodología
}

El estudio se realizó con una perspectiva cualitativa desde el enfoque hermenéutico, dado su potencial para un acercamiento interpretativo a las visiones y los significados de los integrantes de las parejas, sobre la experiencia de violencia en la relación (Gadamer, 1993). La decisión de enmarcar el proceso investigativo en este enfoque estuvo también sustentada en las posibilidades que brinda para la comprensión de tales visiones y significados como textos susceptibles de múltiples lecturas (Ricoeur, 2004).

El proceso cualitativo se sustentó en los momentos metodológicos de exploración, focalización y profundización que plantea Galeano (2004). Como técnicas se utilizaron las entrevistas exploratorias a profundidad y las historias de vida, con el fin de comprender, desde las visiones de cada uno de los participantes, la realidad que se teje y que sostiene la relación de pareja en el marco de la violencia conyugal. 
De la tensión en el ejercicio de los roles de género a la violencia conyugal como pauta relacional

Se trabajó con dos parejas residentes en Manizales con patrones relacionales de violencia, de estratos socioeconómicos 2 y 3 respectivamente. La primera con organización familiar de diada conyugal en unión matrimonial (para efectos del estudio ${ }^{1}$, Rosario y Fredy), hombre de 42 años, de Manizales, con formación profesional en Ingeniería Agronómica, desempleado al momento del trabajo de campo y la mujer de 34 años, nacida en Manizales, con formación profesional en Ciencias Sociales y vinculada laboralmente con una institución privada. La segunda pareja reconstituida en unión marital de hecho con un hijo de la relación actual (Carmen y Daniel), mujer de 45 años, oriunda de Arauca (Caldas), con formación primaria, ocupación como empleada doméstica por días con dos hijas (de una unión anterior y convive con ellas) y el hombre de 39 años, bachiller con ocupación en servicios generales, quien tiene una hija de una unión anterior (no convive con ella). Ambas con trayectorias de convivencia que oscilan entre cuatro y cinco años de permanencia.

La interacción con los actores se generó a partir de entrevistas individuales, motivadas por las preguntas circulares y estratégicas que iban guiando el proceso y escudriñando en él conocimientos, pensamientos y experiencias vividas por los individuos, y de esta forma se estructuró un proceso de empatía, seguridad y reflexividad, en las tres conversaciones con cada uno de ellos.

Para el análisis de la información se procedió al proceso de categorización, codificación y triangulación de los datos, en un escenario permeado por la reflexión y la pregunta permanente que aportó a una mayor comprensión de la violencia conyugal, lo cual se convirtió en un ejercicio riguroso de confrontación y validación en coherencia con los objetivos de la investigación.

\section{Resultados y discusión}

Los estereotipos de género, presentes en las prácticas y los discursos desde los cuales se configuran los ámbitos organizacional y relacional de la pareja, cumplen un papel determinante en el surgimiento de tensiones asociadas a las expectativas insatisfechas respecto a lo que cada uno espera del otro/a como hombre o como mujer.

En este sentido, se presenta el análisis de las tensiones que, en la relación de las parejas participantes en la investigación, ha generado el surgimiento de la violencia, bien sea como vía de resolución, como forma de decir lo que no se alcanza a expresar de otras maneras, como estrategia para la reorganización del control, entre otras posibles razones para irrumpir en esta pauta de interacción.

\footnotetext{
${ }^{1}$ Son nombres ficticios, para garantizar el anonimato de los participantes y en aras de conservar la confidencialidad.
} 
Tal análisis es planteado desde propuestas de corte relacional como la de Perrone y Nannini (2007), teniendo en cuenta que la violencia, al ser el resultado de un proceso de comunicación particular entre dos o más personas, requiere ser entendida en un contexto relacional y no individual; y la de Sluzki (2012) quien recalca la complejidad de la trampa interaccional a través de la cual la violencia se instala en la pareja.

Desde este marco de referencia, la discusión gira en torno a los siguientes asuntos: los tipos de violencia predominantes en las parejas; las creencias de género construidas en el marco de las historias personales que se presentan en el posicionamiento individual frente a la pauta de violencia; los repertorios habituales de intercambio violento a los que han llegado por medio de los denominados "acuerdos implícitos rígidos"; los aspectos espacial, temporal y temático, a través de los cuales se conforman tales acuerdos y los efectos individuales y relacionales de la violencia (Perrone y Nannini, 2007).

\section{Violencia relacional en la pareja: entre expresiones gestuales-verbales femeninas y el silencio masculino}

En la pareja 1 prevalece una relación en la cual la mujer asume en mayor medida los roles tradicionalmente asignados a lo masculino, mientras el hombre tiene una posición más definida desde aquellos considerados femeninos. Lo expuesto devela organizacionalmente las tensiones surgidas a partir de las expectativas insatisfechas frente al cumplimiento del rol propio y del otro, lo que ha dado lugar a algunas formas de violencia en la pareja. La violencia, como una pauta de interacción habitual en la relación, es reconocida y al parecer naturalizada por sus integrantes:

Por lo menos reconocer que de una mujer a un hombre también puede haber violencia. Como en el caso de nosotros, él puede ser muy grande y yo un llavero al lado de él, pero yo soy la más gritona, tengo el carácter más fuerte, y entonces yo soy la que se la dedico y él se deja. (Rosario, comunicación personal, 20 de agosto de 2016)

De acuerdo con los roles asumidos por los integrantes de la pareja, la mujer ejerce un papel más activo en las expresiones de la violencia verbal y emocional, percibida por el hombre en el trato que le da compañera y, que en palabras de Perrone y Nannini (2007), remiten a la violencia castigo ${ }^{2}$ en donde Rosario asume un lugar de mayor poder en la relación y Fredy en una posición de sometimiento que termina por aceptar:

\footnotetext{
2 "Que tiene lugar entre personas implicadas en una relación de tipo complementario, es decir, no igualitaria" (Perrone y Nannini, 2007, p. 57).
} 
De la tensión en el ejercicio de los roles de género a la violencia conyugal como pauta relacional

\begin{abstract}
Ella sí es un poquito mal hablada cuando está así molesta, sí, hay veces, pues violencia verbal sí, en ese momento y ahora, ese ha sido el problema de ella, como ella es tan explosiva, ella no piensa, sino que ella va diciendo las cosas, dice groserías, lo insulta a uno, lo intenta a uno menospreciar y en ese momento, pues también, esa ha sido la constante, pero igual hay veces que se le sale pues como la piedra, más que todo la violencia verbal. (Fredy, comunicación personal, 28 de julio de 2016)
\end{abstract}

La comprensión del hombre frente a la violencia ejercida por su compañera se realiza a través de la naturalización de los insultos, gritos y ofensas como parte de su personalidad. Así, con afirmaciones como ella "es explosiva e impulsiva", justifica expresiones de "Morrongo, bruto... groserías como: güevón, usted con esas maricadas... gritando y abriéndome los ojos, porque ella cuando se molesta, se enciende rapidísimo” (Fredy, comunicación personal, 28 de julio de 2016).

En este sentido, el hombre también justifica los actos de Rosario en la destrucción de objetos y la autoagresión que, según la Organización Mundial de la Salud (2013), remite al "uso intencional de la fuerza o el poder físico, de hecho o como amenaza, contra uno mismo” (p. 3), y que suelen ser parte del ritual de violencia,

Ella como es tan explosiva, pues violencia contra ella misma, o sea me explico, ella cuando se pone a hablar y pensar en lo económico, en ese momento cogía los celulares o lo que tenía en la mano a destruir todo, a tirar contra la pared o se ponía a darle puños a las paredes, pues era violencia, pero hacia ella misma. (Fredy, comunicación personal, 28 de julio de 2016)

Teniendo en cuenta que la perspectiva privilegiada para el análisis relacional, la participación más activa de la mujer en la pauta violenta no puede entenderse desde la visión tradicional, en la que se asume que en la violencia una persona actúa como víctima y otra como victimario. Por el contrario, se comprende que:

El consenso al que se llega opera en el nivel bipersonal, pero tiene raíces individuales, ya que se apoya sobre la imagen negativa y frágil que cada uno tiene de sí o sobre circunstancias previas que se registran como tales en la historia individual. (Perrone y Nannini, 2007, p. 67) 
De acuerdo con lo anterior, la forma como la pauta violenta llegó a constituirse en esta pareja en un acuerdo implícito rígido ${ }^{3}$ requiere comprenderse a la luz de las creencias de género construidas en el marco de las historias personales de sus integrantes, presentes en el posicionamiento individual frente a la pauta de violencia.

En el caso del hombre, algunos imaginarios sobre la masculinidad aprendidos de la relación entre sus padres, reforzados por la escasa interacción con mujeres y con hombres durante la adolescencia, como consecuencia de vergüenza producida por su inconformidad con algunos rasgos de su aspecto físico, contribuyeron a la construcción de un rol de género distante de las asignaciones tradicionales para lo masculino, expresadas en su relación con Rosario a través de pasividad y dependencia. Es así como recrea la pauta violenta de su madre, al referirse a una similar que percibe por parte de su compañera sentimental: "Una cosa que tiene similar mi mamá y Rosario es que cuando se molestan empiezan a decir cosas hirientes, no piensa, sino que como de la ira empiezan a decir un poco de cosas" (Fredy, comunicación personal, 31 de julio de 2016).

En el caso de Rosario sus aprendizajes de género han naturalizado la violencia ejercida por la mujer, a partir de la posición de superioridad y dominio ejercida por su madre frente al padre, experiencias de vida que se "constituyen en un sistema de creencias al que la persona se atiene y del que se vale para actuar” (Perrone y Nannini, 2007, p. 76).

Esta pauta de dominación femenina en la pareja se convierte para Rosario en un asunto que no logra controlar, en la medida en que considera haber construido en su relación materna, una identidad como mujer temperamental, dominante y controladora, que considera ideal porque le ha permitido posicionarse, aunque le genere dificultades con su pareja:

Mi mamá me hizo a imagen y semejanza de ella, cuando hice el ejercicio, encontramos que yo me veía igual a mi mamá ¿cuál era la falla?, que yo siempre estaba tratando de cumplir la expectativa de mi mamá y no la mía. (Rosario, comunicación personal, 4 de agosto de 2016)

Ahora, dirigido el análisis a los aspectos temático, espacial y temporal, a través de los cuales se conforman tales acuerdos implícitos rígidos orientados a la violencia en la pareja, puede identificarse que, con relación al aspecto temático, es decir, a "los acontecimientos, circunstancias o contenidos de comunicación que desencadenan el proceso" (Perrone y Nannini, 2007, p. 69), la posición evitativa del conflicto asumida por Fredy es un asunto que provoca las actitudes agresivas en Rosario, haciendo que irrumpa la pauta relacional violenta.

\footnotetext{
${ }^{3}$ Pauta relacional en la que surge la violencia, como una forma de sostener a la pareja (Perrone y Nannini, 2007).
} 
De la tensión en el ejercicio de los roles de género a la violencia conyugal como pauta relacional

Esta actitud del hombre la entiende su compañera como expresión de desamor y egoísmo, lo cual también puede comprenderse como otro aspecto temático central en el acuerdo implícito que produce la violencia y que se remite a un discurso de inconformidad centrado en la regulación y control de la organización familiar por parte de Rosario:

Es una de las causas por las que ha habido muchas peleas: es que usted a mí no me quiere, es que usted como es de raro, usted solo piensa en usted, que quiere estar solo, usted apenas para que esté solo, para que se vaya donde su mamá. (Fredy, comunicación personal, 28 de julio de 2016)

Ahora bien, el aspecto temporal pactado a través de la ritualización de la violencia, término que hace referencia a que "el momento en el que se desencadenan la interacción y la cronología de los hechos está predeterminado” (Perrone y Nannini, 2007, p. 69) y, en este sentido, los episodios violentos suelen iniciar cuando la tensión acumulada es expresada por la mujer con palabras y gestos, frente a los cuales el hombre responde con silencio, elemento asumido por ella como una forma de maltrato que incrementa el malestar y percibe la necesidad de que él se implique en la conversación.

Este malestar es expresado a través de quejas y reclamos sobre el meta-mensaje que percibe en esta respuesta: "ausencia de atención por parte del hombre". Esta pauta inicial de la violencia puede leerse a partir de la necesidad de Rosario de sujetar a Fredy en una dinámica relacional de pareja, centrada en el contacto físico y la emocionalidad.

Cuando el maltrato verbal avanza hasta el ataque físico parece activar en ambos el reconocimiento de la mayor fuerza física del hombre frente a la mujer, lo que produce una alerta sobre las consecuencias de la escalada que tomen las agresiones mutuas. Esta dinámica puede apreciarse en los siguientes relatos:

Yo la contengo, aunque una vez sí, mejor dicho, de esos momentos que no todos los días uno está bien, en ese momento yo venía como muy estresado, no me acuerdo por qué y fuera de eso ella empezó pues como a atacarme, entonces yo me sentí muy mal y cogí de aquí [muestra el cuello], la cogí y ella se asustó muchísimo y se quedó así. ¿A este qué le pasó? Yo la tiré a la cama, pero para que se callara, la cogí de aquí, cállese ya, porque ella habla y habla y eso pues como que lo aturde a uno. Esa fue como de las pocas, casi que la única vez desde que yo estoy con ella que ocurre una cosa de esas, eso así pues muy excepcional. (Fredy, comunicación personal, 28 de julio de 2016) 
Un día Fredy cogió una puerta y yo le estaba diciendo, pero es que esto, esto, esto, pues a mí no me parece y cogió y mandó la mano y esa puerta; yo casi me muero, porque él es muy grande, por ejemplo, mi papá lo ha controlado, pero es muy complicado el tema. (Rosario, comunicación personal, 13 de agosto de 2016)

Con relación al aspecto espacial, es decir, al territorio donde se admite la violencia, el lugar donde se desarrolla la interacción violenta, se encuentra que en esta pareja el proceso de escalada del conflicto está designado al territorio íntimo, “al hogar”. En cambio, las fronteras para la descalificación gestual y verbal que usualmente realiza la mujer al hombre no están tan delimitadas con relación al espacio público, existiendo permisividad para llevarlas a cabo en presencia de integrantes de la familia extensa y de amigos.

Para terminar el análisis de la dinámica de violencia en la pareja se alude a las situaciones desencadenantes de la misma. Al respecto se encuentra que esta impacta de forma significativa a la mujer en la parte emocional, al encontrar que a través de las agresiones no logra tener el control y el poder en la relación de pareja, además que la imagen que proyectaba de agresividad ha dejado de generar miedo hacia el otro y, entre tanto, empieza a asumir posturas corporales y gestuales obteniendo indiferencia, hastío y violencia verbal de parte de su compañero, distante de las actitudes que advertían sobre la pasividad de él.

\section{Pauta interaccional simétrica de la violencia: entre la separación y la sujeción}

La dinámica relacional de la pareja 2 se comprende a partir de las tensiones producidas entre los roles asumidos por el hombre y por la mujer, como pautas tradicionales regladas por los estereotipos de género que han legitimado la convivencia como pareja y como familia, pero que en la vía de las expectativas en el ejercicio de los roles de género significan situaciones de violencia.

En este sentido, desde el inicio y trayectoria de la vida en pareja, el hombre ha generado una relación de dominación, pertenencia y control sobre la mujer, a partir de una actitud masculina constructora de una identidad asociada a la fuerza y la agresividad hacia la otra, y en donde sus discursos y prácticas se orientan a legitimar un escenario de violencia permeado por los celos, llegando a "justificar las actitudes represivas violentas contra su mujer si cree que atenta contra su exclusividad en el terreno del placer sexual” (Ravazzola, 1997, p. 48) y considerarse el dueño de ella, como se plantea en el siguiente relato:

En la primera agresión ella estaba en embarazo y tuvimos un problema por eso, a ella no le gustaba bajar a Arauca en diciembre que porque el ex marido de pronto le pegaba, yo le decía: entonces 
De la tensión en el ejercicio de los roles de género a la violencia conyugal como pauta relacional

usted tiene algo con él y ella me decía: no, sino que ustedes son muy jodidos, siempre hacía pensar que tenía algo con alguien y me daba ira y cuando estoy así reacciono de forma agresiva, me expreso de forma violenta, porque hablo duro, no digo palabras, se me ve la inconformidad. (Daniel, comunicación personal, 1 de agosto de 2016)

Ante la situación planteada, se identifica que desde el comienzo de la relación de pareja, el hombre, en su calidad de proveedor económico, ha asumido prácticas acordes con el modelo de masculinidad legitimado por la cultura patriarcal, justificando así la violencia en el sentido de posesividad hacia su mujer, al sentir que tiene el poder en la relación y el dominio de la familia.

Por su parte, la mujer manifestaba claridad frente al estereotipo de género de los hombres dominantes que violentan a las mujeres, lo cual inicialmente representaba una práctica centrada en la prevención y el no exponerse a situaciones de riesgo, en coherencia con la decisión de continuar la relación de pareja enmarcada en la posibilidad de garantizar el sostenimiento económico de sus hijos y cumplir con el ideario femenino, "sumiso, nunca agresivo, altruista, que no se destaque y que no cuestione el liderazgo de su marido” (Ravazzola, 1997, p. 48).

Cabe agregar que otra forma de violencia presente en la relación de pareja es el chantaje y la amenaza, como aspectos manifiestos por el hombre hacia la mujer, con el fin de vincularla al sistema de control y frente a la necesidad de centrar la atención hacia él, los cuales "se efectúan a través de la invitación a colaborar, a evitar lo peor, a no complicar la situación, a evitar el sufrimiento, no hacer sufrir a los demás" (Perrone y Nannini, 2007, p. 154).

Desde la mirada de los integrantes de la pareja, la violencia tiene diferentes significaciones dependiendo del lugar que cada uno la asuma. Así, para Carmen se relaciona con lo verbal y para Daniel cobra sentido desde sus discursos y algunas prácticas que vivencia en la cotidianidad, frente a las cuales reconoce que se torna agresivo e incurre en situaciones de violencia:

Agredirnos de vez en cuando, es más que todo lo que nos decimos. (Carmen, comunicación personal, 25 de julio de 2016)

Porque yo soy una persona que hablo, pero llego a un límite que me salgo de casillas y me pongo agresivo, incurriendo en la violencia. (Daniel, comunicación personal, 1 de agosto de 2016)

Hasta este momento se puede visibilizar la violencia en el plano verbal y en una dirección del hombre hacia la mujer, pero se empiezan a configurar diferentes manifestaciones físicas 
que acompañan las interacciones de la pareja y que el hombre y la mujer se constituyen en “participantes” de la interacción violenta (Perrone y Nannini, 2007).

Se construye un espacio recíproco de convivencia de violencia conyugal que legitima y justifica las actuaciones de la mujer como una forma de desligarse del control y el poder ejercido por Daniel, frente a lo cual Carmen encuentra en las secuencias de los hechos violentos una forma de manifestar su inconformidad y objeción que no solo se reflejaba en los discursos, sino también en las prácticas.

La pauta relacional violenta que se empieza a configurar en la pareja establece, en los mensajes verbales y no verbales, las justificaciones que tiene cada uno para seguir la secuencia del otro como una forma de dirimir el conflicto, pero que finalmente se agudiza, así Daniel considere que sus actuaciones están tratando de mediar y por el contrario evidencia la forma en que cada uno de los integrantes de la pareja define la continuación de la violencia (Perrone y Nannini, 2007).

En este sentido, la violencia verbal viene acompañada de manifestaciones físicas que caracterizan las interacciones de la pareja en la vía de sostener la relación o de buscar soluciones a las situaciones presentes, asuntos dimensionados por Daniel y Carmen como aspectos leves que no contienen la fuerza para hacer daño y lastimar al otro, de tal forma que "desestiman o asignan poca importancia a las primeras manifestaciones de violencia” (Ravazzola, 1997, p. 43).

Él sí me ha dado pelas, pero no tan fuertes y yo le respondo con la mano, pero mis puños qué le van a dar. (Carmen, comunicación personal, 25 de julio de 2016).

Ella dice que yo la agredí y que luego ella me mordió, yo me acuerdo que estábamos en la cama y yo le tenía el brazo y le dije: ¿pero dígame que es lo que yo le hago? Ay nada, nada; entonces yo me acuerdo que ella me mordió el brazo, yo puedo casi que jurar que fue así, decir que yo tenía ira como para matarla, no, es que yo nunca la he tropeado o golpeado, han sido cosas de roces nada más. Ella me lleva al extremo y yo me dejo llevar al extremo también, ella no para y yo tampoco paro, yo me acuerdo que ella me mordió, 'pero ¿por qué me muerde?, se enloqueció, no me muerda', al instante me dio rabia, cogí y le puse la cara sobre la cama, ahí me di cuenta que estaba en el suelo con ella y yo estaba encima de ella, pero no apoyado. (Daniel, comunicación personal, 1 de agosto de 2016) 
De la tensión en el ejercicio de los roles de género a la violencia conyugal como pauta relacional

Estos relatos dan cuenta de episodios de fuerza y confrontación narrados por Carmen y Daniel frente a los cuales no tienen la capacidad de controlar y, de esta forma, tampoco existen posibilidades de autoprotegerse y evitar cada hecho violento (Perrone y Nannini, 2007). Además, se evidencia una serie de secuencias que caracterizan la violencia, un repertorio que se vuelve reiterativo, el cual obedece a una "trampa relacional, donde la violencia aparece como una necesidad de mantener el equilibrio entre cada uno de ellos" (Perrone y Nannini, 2007, p. 67). Para este caso, el equilibrio se representa, en ella, a través de las expresiones verbales, y en él, en lo físico.

Las experiencias vivenciadas con la familia de origen le aportan a Daniel una imagen negativa de la figura masculina que se desvincula del rol estereotipado frente a lo productivo, pero sí de control y dominación a través de prácticas violentas. Al ser reconocidos en la relación con su pareja, estos aspectos le otorgan sentido en la medida que él es proveedor económico y, por tanto, es quien debe asumir el liderazgo de la familia.

A partir de lo anterior, se puede considerar que la pareja se vincula en acciones secuenciales e interaccionales de la relación, aspectos que en palabras de Perrone y Nannini (2007), pueden estar vinculados con la violencia castigo con simetría latente ${ }^{4}$, en donde la mujer trata de corresponder al sistema de violencia perpetuado por su compañero en el sentido de protegerse ella y a sus hijas, quienes han quedado expuestas en la dinámica interaccional de la pareja, inicialmente al considerarse como las causantes del conflicto, pero también al estar implicadas en las acciones violentas. "Primero me decía: esta hijueputa y yo calladita, nos decimos palabras feas, hasta que un día dije: que no me volvía a dejar decir, me cansé de que me dijera ası" (Carmen, comunicación personal, 25 de julio de 2016 ).

Porque yo antes era con la cabeza agachada, nunca le decía nada, callada y luego sí me volví muy grosera y él ha cambiado y la grosera ahora soy yo o él me dice algo y yo le digo lo mismo a usted. (Carmen, comunicación personal, 25 de julio de 2016)

Esa pauta relacional de la pareja no permite la comprensión de la violencia en su total magnitud y reconocer las implicaciones que conlleva, por el contrario, se minimiza, como una forma de perder la sensibilidad y el dolor frente a lo que les pasa y las consecuencias que implica para ellos y para la familia en general, lo cual atiende al concepto de doble ciego de von Foerster (como se citó en Ravazzola, 1997):

\footnotetext{
4 "Se observa cuando el sujeto que se encuentra en la posición baja, obligado a sufrir el castigo, se resiste a pesar de la relación desfavorable de fuerzas" (2007, p. 62).
} 
Consiste en que la repetición de los patrones de conducta (...) se vuelve posible debido a que los protagonistas "no ven que no ven" y siguen una lógica que ellos perciben como coherente, lo que les impide tomar conciencia del significado y de las consecuencias perjudiciales de sus propias conductas. (p. 90)

La actitud del doble ciego se percibe en la pareja como una forma de sujeción de la relación, en la medida que el hombre pueda continuar asumiendo el rol productivo en la familia y la mujer dedicada al ámbito doméstico, como pautas tradicionales que determinan las funciones y que son importantes para ellos. No obstante, se orientan sobre expectativas insatisfechas frente a las cuales, el hombre no logra asumir la socialización y crianza de sus hijastras.

De otra parte, al centrar el análisis en el acuerdo implícito propuesto por Perrone y Nannini (2007), se referencian los aspectos temático, temporal y espacial que caracterizan la violencia conyugal; algunos de ellos se vuelven reiterativos, no que continúen juntos. Referente al asunto temático, se presenta con relación al rol reproductivo, debido a que la mujer no deseaba asumir nuevamente la maternidad, situación detonante de expresiones verbales y no verbales, descalificaciones y todo tipo de agresiones de forma recíproca, en donde al parecer el control ejercido por Daniel incidió en una pauta simétrica de violencia en Carmen y desde allí se desencadenan las mayores situaciones de dificultad en la relación y específicamente en la familia.

En lo referente al aspecto temporal, el momento en que se desencadenan los hechos violentos tiene que ver con la decisión de realizar las labores domésticas de forma conjunta y no llegan a acuerdos, frente a lo cual se desatan diferentes mensajes verbales y no verbales que terminan con agresiones físicas y que en palabras de Daniel obedecen a las provocaciones que le genera Carmen.

Con relación al aspecto espacial, las acciones violentas se presentan en el ámbito de lo íntimo, es decir, en el hogar en diferentes partes de la vivienda, pero generalmente con la tendencia de terminar en el piso o en una cama, al parecer, sin darse cuenta del lugar en donde culminan los hechos. De igual forma, en ocasiones se presenta la violencia en presencia de los hijos y en una de estas situaciones se vio involucrada la hija menor.

Es así como, al vincular a la hija menor en la situación de violencia de la pareja, permite comprender la noción de límite o frontera propuesto por Perrone y Nannini (2007), lo que significa para Carmen tolerar todo tipo de acciones violentas hacia ella, con excepción de que no se involucre a las hijas y poder garantizar su protección.

Tal como se ha narrado el fenómeno de la violencia en esta pareja, afecta de forma importante la vida cotidiana y la dinámica de las relaciones, pero no se puede desconocer la incidencia 
De la tensión en el ejercicio de los roles de género a la violencia conyugal como pauta relacional

en todo el grupo familiar y, antes que constituirse en un escenario de convivencia protectivo, genera todo tipo de vulneración a los derechos humanos, especialmente a los de niños, niñas y adolescentes, quienes inicialmente se distanciaban, pero en ese momento renuncian a ese trato hacia ellos. Este asunto resulta igualmente polarizado en el sentido que las hijas buscan proteger a su progenitora y el hijo de la pareja al padre.

Ahora bien, los discursos de Carmen expresan el cansancio y malestar en la relación de pareja ante el aumento de los hechos violentos y el desacuerdo que le genera la vinculación de su hija al escenario de violencia, con lo cual siente que sobrepasó el límite, "que constituye el último bastión de la dignidad, de la imagen positiva de sí y se rompe el vínculo de pareja o se produce una grave escalada de violencia seguida de la separación” (Perrone y Nannini, 2007, pp. 70-71).

En este sentido, la decisión de Carmen de irse de casa ante la última situación de violencia puede ser significada como una fuente de regulación para dirimir los conflictos y una de las consecuencias de las acciones violentas. Asimismo, Daniel refuerza esa situación con expresiones de culpa hacia la mujer, que reiteran la necesidad de estar separados.

Sobre la base de las consideraciones anteriores, Carmen y Daniel parecen definir con claridad para cada uno y para el otro la necesidad de separación, pero en contraste con las prácticas manifiestan la tendencia a estar juntos, debido a que el hombre asegura el sostenimiento económico y material, además la posibilidad de que los hijos puedan continuar estudiando y no se pierda el vínculo parental con el niño; y por su parte, la mujer se convierte en el soporte emocional para el hombre, situaciones que conllevan a que estén nuevamente juntos.
Él me decía que si me iba no volvía con él y en cambio me dijo que pidiera la plata y que volviera, que le hacíamos mucha falta, yo creo que nos quiere mucho y si me fui, era por el problema con él y no porque me mantenga con hombres. (Carmen, comunicación personal, 3 de agosto de 2016)

Es importante señalar que las diferentes situaciones de violencia presentes en la pareja le permiten a Carmen y Daniel reconocer los efectos que conlleva en su dinámica relacional ese tipo de actuaciones, por lo que refieren tener mayor conciencia de las implicaciones para la vida e integridad de las personas. Estos discursos, orientados sobre el fundamento del respeto, las promesas del buen trato, a la expectativa de que realmente trascienda a las prácticas, con la clara convicción de continuar sobre los estereotipos de género que vinculan los roles económicos al hombre y la domesticidad al igual que la socialización de los hijos a cargo de la mujer.

Se esperaría que las palabras se manifiesten en hechos reales de respeto en la relación y no se queden en promesas incumplidas que conllevan a naturalizar los hechos violentos y transitan 
por el ciclo de la violencia de forma reiterativa, sin objetar la posibilidad de solucionar los conflictos a través de prácticas dialógicas que permitan negociar intereses y llegar a acuerdos que redunden en la calidad de las relaciones de pareja y de la familia en general, y no recurran en el efecto hipnótico que anestesia e invisibiliza el malestar, la capacidad de control y el dolor en las acciones violentas (Ravazzola, 1997).

\section{Conclusiones}

En síntesis, la violencia en las relaciones de pareja se configura como un mecanismo de control y dominación que se instaura a partir de necesidades e intereses pero que desconoce los límites de actuación en la medida que conlleva acciones en el orden de lo verbal, emocional y físico. En este sentido, se puede ejercer en una sola dirección del hombre hacia la mujer o de la mujer al hombre; sin embargo, dadas las situaciones que emergen en las dinámicas de las parejas participantes de la investigación, es posible considerarla como un fenómeno interaccional, bidireccional y recíproco en el que los protagonistas de las acciones violentas son igualmente responsables de las interacciones generadas en la cotidianidad (Perrone y Nannini, 2007).

Significa entonces que en la dinámica interaccional de la pareja 1, a partir de las tensiones producidas por los cambios en los roles domésticos asumidos por el hombre y los productivos a cargo de la mujer, se presentan situaciones de violencia dado que se apela por la masculinidad, centrada en la autoridad, la fuerza y la impulsividad, aspectos característicos para este caso en lo femenino, lo cual evidencia una contradicción entre los roles que se asumen y las expectativas que se tienen. De esta forma se teje un espacio de violencia, inicialmente de la mujer hacia el hombre y posteriormente en una relación igualitaria de agresión. En este sentido, se conectan los reclamos en relación con las experiencias construidas mediante las historias personales, pues a partir del proceso de socialización se han moldeado actuaciones similares a las referidas por la vía intergeneracional.

Las relaciones de violencia conyugal en la pareja 2 se construyen a partir de los roles reproductivos de crianza y cuidado, sumado a los económicos, derivados de la cultura patriarcal que establece el poder del hombre sobre la mujer, reproduciendo el estereotipo en el que "frecuentemente todos los integrantes del grupo familiar, incluidas las mujeres, consideran que ellas deben ser las cuidadoras de todos y las organizadoras de la vida doméstica, incluso si trabajan fuera todo el día”, lo cual se "agudiza cuando el hombre experimenta que se deteriora o se pierde su capacidad de proteger económicamente a la familia y por lo tanto, ve disminuido su poder" (Di Marco, Faur y Méndez, 2005, p. 113).

En efecto, reflejan claridad de que estos discursos se asumen de forma cotidiana pero, al compararlo con las prácticas, genera violencia en la medida que el hombre desea involucrarse en la socialización de la hijastras como una forma de perpetuar el dominio y control sobre la 
De la tensión en el ejercicio de los roles de género a la violencia conyugal como pauta relacional

familia, frente a lo cual la mujer se resiste, opta por generar límites y responder con acciones violentas, aunque reconoce que su situación económica y material depende de él, por lo que se sujeta a la relación antes que abandonarla.

\section{Referencias}

Beck, U. y Beck-Gernsheim, E. (2001). El normal caos del amor. Buenos Aires, Argentina: Editorial Paidós.

Di Marco, G., Faur, E. y Méndez, S. (2005). Democratización de las familias. Buenos Aires, Argentina: Área de Comunicación UNICEF.

Facio, A. y Fries, L. (1999). Feminismo, género y patriarcado. Revista sobre Enseñanza del Derecho de Buenos Aires, 3(6), 259-294.

Gadamer, H. (1993). Verdad y método. Salamanca, España: Editorial Sígueme.

Galeano, M. (2004). Diseño de proyectos en la investigación cualitativa. Medellín, Colombia: Fondo Editorial Universidad EAFIT.

Giddens, A. (2000). Modernidad e identidad del yo: el yo y la sociedad en la época contemporánea. Barcelona. España: Editorial Península.

Giddens, A. (2003). La constitución de la sociedad. Bases para la teorías de la estructuración. Buenos Aires, Argentina: Editorial Amorrortu.

Hernández, I. (2014). Violencia de género. Una mirada desde la sociología. La Playa, Cuba: Editorial Científico-Técnica.

Illanes, J. (2011). Desafíos y continuidades en la conyugalidad a distancia. Revista Latinoaméricana de Estudios de Familia, 3, 146-173.

Illouz, E. (2012). Por qué duele el amor. Buenos Aires, Argentina: Katz Editores.

Iturrieta, S. (2001). Perspectivas teóricas de las familias: como interacción, como sistemas y como construcción social. En S. Iturrieta. (Ed), Conflictos familiares ¿Cómo resolverlos? (pp.182). Antofagasta, Chile: Ediciones Universidad Católica del Norte.

Lamas, M. (1999). Usos, dificultades y posibilidades de la categoría género. Revista Papeles de Población, 5(21), 147-178. 
Palacio, M. C. (2004). Familia y violencia familiar: de la invisibilización al compromiso político. Un asunto de reflexión sociológica. Manizales, Colombia: Editorial Universidad de Caldas.

Perrone, R. y Nannini, M. (2007). Violencia y abusos sexuales en la familia. Buenos Aires, Argentina: Editorial Paidós.

Ravazzola, M. (1997). Historias infames: los maltratos en las relaciones. Buenos Aires, Argentina: Editorial Paidós.

Ricoeur, P. (2004). Tiempo y narración. Buenos Aires, Argentina: Siglo XXI Editores.

Rubin, G. (1975). El tráfico de mujeres: notas sobre la economía política del sexo. Nueva Antropología, 8(30), 94-145.

OMS. (2013). Informe mundial sobre la violencia y la salud. Recuperado de https://www.who. int/violence_injury_prevention/violence/world_report/en/summary_es.pdf.

Scott, J. \& Butler, J. (1992). "Experiencia”. Feminists Theorize the Politica. New York: Editorial Routledge.

Sluzki, C. (2012). Las "narrativas" en la terapia con víctimas de violencia. Recuperado de http:// psicologossalta.com.ar/ las-narrativas-en-la-terapia-con-victimas-de-violencia/. 